Copyright (C) 2021 by Cherkas Global University

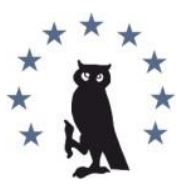

Published in the the USA

International Journal of Media and Information Literacy

Has been issued since 2016.

E-ISSN: $2500-106 \mathrm{X}$

2021. 6(2): 338-353

DOI: 10.13187/ijmil.2021.2.338

https://ijmil.cherkasgu.press

\title{
Correlation of Technostress Creators with Employees' Work-Life Balance in the Context of Journalists' Use of Information and Communication Technology at Work: Moderating Role of Self-Efficacy
}

Adamkolo Mohammed Ibrahim ${ }^{\text {a , * }}$, Mohd Nizam Osman ${ }^{\mathrm{b}}$, Ahmed Lawal Gusau ${ }^{\mathrm{c}}$, Phuong Thi Vi ${ }^{\mathrm{d}}$

${ }^{a}$ University of Maiduguri, Nigeria

b Universiti Putra Malaysia, Malaysia

c Abdu Gusau Polytechnic, Zamfara, Nigeria

d TNUS - University of Sciences, Vietnam

\begin{abstract}
Technical pressures otherwise known as "technostress" because of the use of work-related information and communication technology (ICT) are increasingly causing stressful experience to journalists in the newsroom. Existing research has shown that journalists' attitudes and performance are adversely affected by technostress creators, and not much is understood about their effects on non-working lives especially in the Global South context. This study aimed to close this research void by examining the relationship between technostress creators and "work-life balance" with "job self-efficacy" as a mitigating factor. Employing a survey questionnaire, the data was collected from 300 full-time Nigerian and Vietnamese journalists. Key findings showed that (i) technostress creators were negatively associated with work-life balance; and (ii) the negative relationship was moderated by work self-efficiency. These findings enrich the technostress research by providing an insight into the influence of technostress creators on journalists' work-life balance and highlight how to cope with technostress situations.

Keywords: advanced technologies, employees, job self-efficacy, ICT use at newsroom, journalists, self-efficacy, technostress creators, work-life balance.

\section{Introduction}

Over the past decades, the rapid developments in information and communication technology (ICT) have had a tremendous impact on organisations and individuals. The adoption of ICT stimulates job and business processes by redefining old organisational structures and creating new jobs. Even businesses that are traditionally left behind in ICT adoption such as journalism, construction and agriculture are now racing towards using it to increase their competitiveness (Apooyin, 2014; Rao, 2007; Mwakaje, 2010). For employees around the world, deployed ICT has made it possible to link at any time "to support and improve business processes and regulatory decision-making" (Hunton et al., 2003; Chandra et al., 2012). Not only is the use of ICT in processing and production levels increasingly becoming imperative in organisations but also becoming essential for the improvement of the quality of life of individuals. For example, the use of ICTs such as smart mobile devices, laptops and other various types of computers and computerrelated technologies improve the quality of life - making hustle-free and easier work easier (Molla, Heeks, 2007; Khan, Garvinba, 2010).
\end{abstract}

\footnotetext{
${ }^{*}$ Corresponding author

E-mail addresses: adamkolo@unimaid.edu.ng (A.M. Ibrahim)
} 
Despite the proliferation of ICT has brought about a great deal of benefits, it is likely to have harmful and unintended consequences on users. Scholars and professionals have consistently expressed worries about the "negative" repercussions of ICT, for example, rising domestic and labour conflicts, stress, "information overload", cybercrime, phishing, etc. (Brivio et al., 2018; Vranjes et al., 2017). This study focuses on one of the negative repercussions of the use of ICTs known as technostress, which is the stress experienced by end-users of ICT (Ragu-Nathan et al., 2008). Research has shown the "negative" repercussion of technostress creators on workers' "satisfaction, productivity and organisational commitment" (Brivio et al., 2018; Ragu-Natahan et al., 2008) and that, workers get overwhelmed "and develop an intention to quit the work because of technostress” (Ayyagari, 2012; Ayyagari et al., 2011; Ragu-Nathan et al., 2008).

Regarding the use of ICT in a private context, studies have shown that technology users experience fatigue, enervation "and stress" because of the overuse of ICTs (Apooyin, 2014; Samaha, Hawi, 2016) despite the use of technology "is optional and users always have the option to stop using it when they feel stressed" (Lehmann-Jacobsen, 2017). In disparity, however, for the purposes of working in or for organisations the use of ICT is compulsory. Hence, employees must use and interact with ICT that is innovatively and constantly changing. Hence, factors causing technostress are increasingly becoming a serious organisational issue, which affects "the physical and mental" wellbeing of workers (Apooyin, 2014; Brivio et al., 2018).

The enormous achievements attributable to ICT in the current information age "has (sic) been allegedly tinted with gloom" because of the implications of ICTs for users who, often, must use them in their routine jobs. In the process of adapting to increasingly complex techniques, however, more users experience physical and emotional stress. For instance, in the past 10 to 15 years, organisations have "experienced significant changes as a result of ICTs and the subsequent digital transformation" (Mcafee, 2006: 1; Matt et al., 2015; Ngoc, 2016). These dynamic changes that are "technological, organisational and cultural" in nature "have redefined work and enterprise models and competition". For instance, as demonstrated by the relocation from "Web 1.0 to Web 2.0" and from "Enterprise 1.0 to Enterprise 2.0" internet technology and enterprise models, "ICT offers individuals and organisations increased productivity and efficiency" (Mcafee, 2006: 1).

Nonetheless, through "misuse, abuse and overuse", the application of ICT in organisational jobs can cause a peril to both the workers and the organisation; thus, giving rise to mental health risks and poor performance turnout associated with technostress (Brivio et al., 2018; Gaudioso et al., 2017; Lehmann-Jacobsen, 2017; Mcafee, 2006: 1; Pihl-Thingvad, 2015). With reference to this discourse, the question to ask is: How do workers perceive stress-inducing ICTs regarding the balancing between their job and non-job life? This question becomes relevant due to the demanding nature of the job with most workers such as engineers, journalists, technicians, etc. especially in poor countries, who often lead miserable lifestyles and suffer from mental illnesses after retirement (Lehmann-Jacobsen, 2017).

\section{Material and methods}

Research Design, Population, Sample and Sampling Technique: A quantitative survey approach was used to gauge the responses of a sample of 300 full-time journalists from Nigeria. The sample was drawn from a total population of 87,784 journalists $(46,784$ Nigerian journalists and 41,000 Vietnamese journalists). However, as of July 2021, only 5,784 of Nigerian journalists are registered on the website of Nigeria Union of Journalists (NUJ), the country's umbrella union for all journalists. No differentiation was made between the various categories of journalists print, broadcast, online, freelancers, journalists working in public media organisations, etc. The sample sizes were determined using the Taro Yamane's sampling technique.

A multistage random sampling was used to draw the samples: (i) in stage one, a sample size of 374 was drawn from the population of Nigerian journalists while 396 was drawn from the population of Vietnamese journalists; (ii) in stage two, the two samples were combined thus, yielding a new population size of 770; (iii) in stage three, a final sample size of 263 was obtained. For convenience purposes, it was rounded up to 300. Thus, a final sample of 300 full-time journalists who used various ICTs at work (such as digital camera, microphone, computer, mobile devices, digital office and industrial printing machines, digital studio news processing and production equipment, etc.) was surveyed. 
An online survey number randomising app, 'SurveyMonkey' was used to generate the random numbers for the selection of the samples at stages (ii) and (iii) mentioned above. With the help of the officials of NUJ in Nigeria and Vietnamese Journalists' Association (VJA) in Vietnam, e-copies of the questionnaire were sent via e-mail and WhatsApp to the journalists who had been selected in the final sampling stage but could not be met personally for a face-to-face questionnaire administration due to logistic reasons. The confidentiality of the participants' responses was assured and completed the survey forms. The survey form was in English and was translated (e.g., Brislin, 1980) into Vietnamese language for participants from Vietnam. The response rate was $99 \%(n=297)$ having failed to retrieve the questionnaire from three $(1 \%)$ participants. The average age of the participants was 29.72 years $(\mathrm{SD}=2.67)$. Nearly one-thirds $(28.6 \%, \mathrm{n}=85)$ of the participants are female, nearly half $(45.5 \%, \mathrm{n}=135)$ of them were married, a vast majority $(88.6 \%, n=263)$ of them were bachelor's degree holders or higher degrees with only few $(2.4 \%$, $\mathrm{n}=7$ ) of them not having a bachelor's degree.

Instrumentation: A five-section questionnaire was designed and used to collect the data from the participants because all the 17 items used in this study's scale were adopted from pre-validated studies, a pilot-test was deemed unnecessary; hence, it was not performed. Section 1 was on the participants' demographics, Section 2 was on the technostress creators construct, Section 3 was on the Work-life balance construct, Section 4 was on the Job self-efficacy construct and Section 5 was on the control variables. The data were collected using a combination of face-to-face selfquestionnaire administration and an e-mail administration. The sampling frames for both Nigerian and Vietnamese samples of the participants were obtained from NUJ and VJA, respectively. For the participants that could be reached personally, for a face-to-face administration of the questionnaire was performed whereas for those that could not be reached personally, an e-copy of the questionnaire was e-mailed to them. For a few of them who could not be reached via the e-mail addresses provided, alternative means of communication were employed, especially WhatsApp and Telegram apps.

Measures: (i) Technostress Creators: - The technostress creators variable was gauged with a five-items scale adapted from Ma et al. (Ma et al., 2021) and Tarafdar et al. (Tarafdar et al., 2007) in a similar way with some past studies (e.g., Jena, 2015; Lee et al., 2014). One of the items reads, "I am forced to change my work habits to adapt to new technologies." Possible responses range from (1) strongly disagree to (7) strongly agree. The Cronbach alpha score was .85 , indicating a good reliability; (ii) Balancing Work and Life ("Work-Life Balance): - Brough et al.'s (Brough et al., 2014) four-item scale was employed to measure "work-life balance." The scale has been adjudged to have robust psychometric properties (Chan et al., 2016). One of the items reads, "I currently have a good balance between the time I spend at work and the time I have available for non-work activities." Possible responses range from (1) strongly disagree to (7) strongly agree. The Cronbach alpha score was .92, indicating a very good reliability; (iii) Job Self-Efficacy: - Job self-efficacy variable was gauged with a three-item scale developed by Spreitzer (Spreitzer, 1995). One of the items reads, "I am self-assured about my capabilities to perform my work activities." Possible responses range from (1) strongly disagree to (6) strongly agree. The Cronbach alpha score was .90, indicating a very good reliability; (v) Control Variables: - Workload variable was controlled "because workload influences work-life balance" (Ma et al., 2021). Workload was measured using the five-item scale developed by Spector and Jex (Spector, Jex 1998). One of the items reads, "My work demands a lot from me." Possible responses gauged using a five-point Likert scale range from (1) seldom to (5) several times a day, and had a Cronbach alpha score of .89, indicating a good reliability.

\section{Discussion}

Concept of journalism in the context of ICT use and work-life balance. Initially, academics were drawn to the study of work-life balance and job satisfaction because of the variables of social forces and changes in organisational goals (Pollard, 1995; Stam, Underwood, 1993). The entire media industry landscape was transformed as cutting-edge information and communication technology (ICT) transitioned from traditional media to the digital age (Stam et al., 1995). New job opportunities have emerged, audience demand has shifted, and advertiser requirements have shifted (e.g., see Barrett, 1984; Beam, 2006; Perez, Cremedas, 2014). As a result of these changes, journalists have been reflecting on the increasingly pressurising job-demands, importance of their profession and the potential of their future career paths. With morale dwindling, many people considered the possibility of layoffs and research into the phenomenon began seriously (Yu, 2021). 
People began to express their dissatisfaction with the journalists and news media in earnest. To gain a better understanding of the factors that led to this, researchers have attempted to present specialised areas of research on negative or positive influences ICT use on a journalist's job performance and work-life balance. For example, one specialised study - "burnout" - in industry (Macdonald et al., 2016) explores the negative effects of technological development on job satisfaction and work-life balance factors (Lim, Lim, 2013), This type of study, according to the press, investigates the negative effects of ICT advancement on job satisfaction and work-life balance (Yu, 2021).

Many academics believe that journalism is more of a value-driven profession than a profitdriven one (Picard, 2005 cited in $\mathrm{Yu}, 2021$ ). Motivators (also known as intrinsic factors) are necessary for people to be happy in their jobs and be able to maintain work-life balance, according to Herzberg's motivation and hygiene theory, whereas hygiene issues (also known as external factors) are indicators of job dissatisfaction (or job dissatisfaction indicator). Journalists have become increasingly interested in how intrinsic factors (such as journalism's professional value) influence work-life balance and job satisfaction in recent decades. The study of journalism as a profession is still in its relatively early stages, with researchers looking into a variety of factors that could affect journalists' work-life balance and job satisfaction (Holyfield et al., 2015). Although work-life balance and job satisfaction are relatively new concept in journalism, they are a wellestablished concept in the business world (Rogelberg, 2007).

Journalists as a profession are a diverse group of people who work in a variety of environments. Because there were no industry-wide standards and they could be practised in a variety of ways, journalists were studied as a profession rather than an art form in the early 2oth century (Cameron, 1967 cited in Yu, 2021). Journalism was defined as "the gathering, preparation, and dissemination of news and relevant commentary, as well as featured material, through mass media such as brochures, newsletters, newspapers, magazines, radio, motion pictures, television, and books" in the late twentieth century (Encyclopedia Britannica, 1989 cited in $\mathrm{Yu}, 2021$ ). Today, journalism is consistently described as a profession in terms of multiple dimensions, including the public service it provides, the objectivity and independence it upholds, the time it takes to report on issues, and the ethics it upholds (Kovach, Rosenstiel, 2001) in their professional lives, and selfsufficiency (Deuze, 2005). According to Wilinsky (Wilinsky, 1964 in Yu, 2021), professionals can self-regulate due to the basic concept of "exceptional autonomy" and the "rules of associations, licencing, and ethics" in place. Overall, autonomy (the value of journalism as a profession) is a motivating factor for work-life balance and is essential to comprehending journalism studies as a profession. This paper looks at how the concept of work-life balance is being communicated in relation to the impact of ICT-induced technostress in the non-working life of journalists.

Technostress and technostress creators. In modern workplaces, "technostress creators" are increasingly "becoming a major source of stress" (Ma et al., 2021). Technostress creators are associated with negative outcomes such as low job satisfaction and low organisational commitment, lower retention and, as Tarafdar et al. (Tarafdar et al., 2014) and Carlson et al. (Carlson et al., 2017) note, "performance and higher levels of work strain."

Research on technostress creators has focused on negative effects in the work domain; not much data exists on the influence of technostress creators on the non-working lives of journalists and other employees. A study explored the relationship between a certain factor of technostress creators (i.e., technology overload) and work-family conflict; however, work-life balance is distinct from work-family conflict (Harris et al., 2015). According to Syrek et al. (Syrek et al., 2013) "Work-life balance is a broader construct that reflects people's evaluation of the ways in which they combine their work roles and life roles." According to Casper et al. (Casper et al., 2018), "It [work-life balance] is a meaningful goal and ideal state for employees [such as journalists]."

Moreover, guaranteeing work-life balance for employees such as journalists is a good way for media management to attract talented job candidates and motivate existing journalists and other employees (e.g., Apooyin, 2014; Lehmann-Jacobsen, 2017; Ofili et al., 2014). As ICT is blurring the dividing lines that set off job and non-work life, achieving a balance between work and non-work life is a constant struggle for journalists and other employees all over the world (Anaeto, 2007; Beam, 2007; Hunter et al., 2017). Technostress creators are becoming unavoidable in the modern organisations; so, it is imperative to investigate their influence on work-life balance and help workers find effective coping mechanisms (Anaeto, 2007; Apooyin, 2014; Beam, 2007; Ma et al., 2021). 
The literature has shown that technostress can be caused by many factors, some of which include "including techno-invasion, techno-overload, techno-complexity, techno-insecurity, and techno-uncertainty" (Brivio et al., 2018: 2; Ragu-Nathan et al., 2008). Techno-pressures like these can cause serious repercussions on individuals and organisations. Cited in Brivio et al. (Brivio et al., 2014: 2), Tarafdar et al. (Tarafdar et al., 2007), Ragu-Nathan et al. (Ragu-Nathan et al., 2008) and Gaudiosso et al. (Gaudiosso et al., 2017) cited in Ma et al. (Ma et al., 2021) have defined techno-invasion, techno-overload, techno-complexity, techno-insecurity, and techno-uncertainty as follows. "Techno-invasion is defined as constant connectivity, without boundaries of space and time, which maintains that employees are continuously available to work requests.... techno complexity, [is] the unpleasant feeling that the new ICTs are multifaceted and require tremendous effort to understand. Techno-insecurity is the perception that ICTs and the constant need to remain up to date can threaten an individual's job.... Lastly, techno-uncertainty causes perceived instability, due to the evolving nature of the work, and associated processes as well as constant introduction of new ICTs" (Ma et al., 2021)

In addition to technical addiction, techno-invasion at the individual ICT user's level requires the extension of job-related tasks "into the worker's private life", thus, undermining the employees' (e.g., a journalist's) work-life balance. Whereas, at the organisational level an overload of "information and communication", or "techno-overload" entails workers (e.g., journalists) receiving information from multiple channels simultaneously. These workers could experience difficulties managing the excessive communication and information they receive "as it may be unclear how to prioritise or best use the information received" (Gaudiosso et al., 2017 cited in Brivio et al., 2018: 2).

Furthermore, the lack of support during the company's ICT testing, implementation and use of, for example, newly-acquired ICTs; the absence of other mechanisms to support ICT; the lack of mechanisms to utilise the information provided by the company; the absence of mechanisms to utilise information and communications; the absence of mechanisms to take advantage of the discomfort and fatigue resulting from multitasking, given that ICT allows more tasks to be accomplished in less time, are some of the additional factors contributing to technostress.

The literature has shown that the prompt provision of technical and organisational support in addition to giving room for staff to participate "in ICT implementation activity and appropriate communication management" allows for a reduction in the emergence of "technostress" in the workplace and "encourage greater well-being and productivity" (Brivio et al., 2018: 2). Hence, the need for this study to be conducted to provide a further understanding on the correlation of technostress creators with work-life balance among employees who use ICT in their routine jobs. All these can negatively affect the work and living conditions of employees (Ma et al., 2021).

Theoretical framework. The theoretical underpinning of the Job Demands-Resources Theory (e.g., Demerouti et al., 2001) was adopted to examine the relationship between technostress creators and "work-life balance". The literature (e.g., Ma et al., 2021) demonstrates that job demands may have negative outcomes; considering that, this study drew a hypothetical assumption that the relationship between technostress creators and the balance of work life, or "work-life balance" is negative. While responding to Bakker and Demerouti's (Bakker, Demerouti, 2017: 275) assertation that "more research is needed to test the Job Demands-Personal Resources interaction", this study explores whether "job self-efficacy", an "personal resource" that significantly cushions "the negative relationship between technostress creators and workers' worklife balance" as Wayne et al. (Wayne et al., 2017) claim.

The Job Demands-Resources Theory uses a positive psychology approach to explain employee experiences in the workplace (Bakker, Demerouti, 2017). Working conditions can be broadly defined as either job requirements or job resources in all occupations, according to the theory's central premise. Work requirements are those aspects of work that necessitate physical and/or mental exertion and are linked to energy depletion as well as psychological and physiological costs (e.g., workload, disciplinary issues, and time pressure) (e.g., see Demerouti et al., 2001). Job resources, in contrast to job demands, are the business elements that enable employees to achieve business objectives, manage work demands and associated physical and psychological costs, and grow and develop in their position (e.g., support for perceived autonomy, professional learning opportunities, relationships with colleagues).

Recent Job Demands-Resources concepts have recognised the role of personal resources in shaping employees' workplace experiences, in addition to job requirements and job resources 
(Xanthopoulou et al., 2007 cited in Granziera et al., 2021). Personal resources, which are subjective assessments of an individual's ability to control and influence their environment (Hobfoll et al., 2003 cited in Granziera et al., 2021), can predict how work demands and work resources affect employee outcomes either directly or indirectly. For example, a journalist's perception of the newsroom climate (a job resource) may be influenced by self-efficacy (a personal resource), resulting in increased feelings of commitment (which is the outcome) (e.g., see Collie et al., 2011). Individual journalists who work in a positive newsroom climate (a job resource) may have a higher level of self-efficacy (a personal resource), which could help them perform better at work (which is the result) (Klassen, Tze, 2014 cited in Granziera et al., 2021).

Correlation between technostress creators and work-life. Brod (Brod 1982: 754) first introduced and then defines the concept of "technostress" as "a condition resulting from the inability of an individual or organisation to adapt to the introduction and operation of new technology." That definition was modified by Tarafdar et al. (Tarafdar et al., 2007) thus: "Technostress is stress from using work-related technology". The scholars discovered that five factors constitute technostress creators, or "technostress creators" namely: "techno-overload, techno-invasion, techno-complexity, techno-insecurity, and techno-uncertainty." According to Tarafdar and colleagues, "techno-overload occurs when employees are compelled to work faster and longer due to work-related technologies [ICTS]."

Those techno stressors, based on the proposition by the Job Demands-Resources Theory, can be conceptualised as job demands (Demerouti et al., 2001; Bakker, Demerouti, 2017), and each occupation has its own set of risk factors associated with negative behavioural outcomes (Bakker, Demerouti, 2017). Among these variables are "job demands and job resources." Job demands, as defined by Bakker et al. (Bakker et al., 2005: 170), are "physical, social, or organisational characteristics of a job that impose psychological and psychological ... costs on individuals." These costs result in adverse consequences such as stress, illness, "decreased commitment, and decreased job performance" (Ma et al., 2021; Tarafdar et al., 2019).

Technostress generators are demanding aspects of employment for many employees. To thrive and survive in the information age, technicians and journalists who work with ICT must make sustained efforts to keep pace with rapid technological advancements (Tarafdar et al., 2019). Techno stressors have been linked to unfavourable effects for most categories of workers using technologies, including "decreased job satisfaction" (Ma et al., 2021), as well as decreased performance and productivity (e.g., Ayyagari et al., 2011; Tarafdar et al, 2014; Tarafdar et al., 2011). Along with job performance, managers and employers worldwide are prioritising work-life balance (Apooyin, 2014; Casper et al., 2018; Lehmann-Jacobsen, 2017; Wayne et al., 2017). Whereas Brough et al. (Brough et al., 2014: 2728) define work-life balance as "an individual worker's subjective assessment of the compatibility of his or her work and non-work activities, as well as life in general."

This one-dimensional definition of work-life balance is derived largely from the work of Kalliath and Brough (Kalliath, Brough, 2008) within the theoretical framework of occupational stress. Work-life balance, according to Brough et al. (Brough et al., 2014), is a result of "resource fluctuations in work environments [such as work arrangements, or workload akin to job demands in the Job Demands-Resources theory]". Job requirements are a negative predictor of work-life balance (Brough et al., 2014; Greenhaus, Powell, 2017; Syrek et al., 2013). According to one theory, "meeting job demands depletes an individual employee's reservoir of resources", resulting in negative outcomes at work and at home according to Apooyin (Apooyin, 2014), Lehmann-Jacobsen (Lehmann-Jacobsen, 2017), and ten Brummelhuis and Bakker (ten Brummelhuis, Bakker, 2012) as cited in Ma et al. (Ma et al., 2021).

Since technostress creators represent job demands and job demands have a detrimental effect on work-life balance, this study assumes that technostress creators will also have a detrimental effect on employees' work-life balance. For instance, technological invasion means that employees will generally deal with work-related issues while at home, limiting their ability to be as involved as they wish and having a negative impact on their personal lives. Similarly, technocomplexity implies that employees must "invest time and cognitive effort" in learning "how to use" new tools and "and staying current" on existing ones (Brivio et al., 2018: 1-2). This investment, whether at work or in leisure, may reduce their effectiveness in important work and life roles, thereby affecting their assessment of their ability to balance work and family life. Given the discourse above, we formulated the following hypothesis: 
H1: There is a relationship between technostress creators and work-life balance.

Moderation analysis: "job self-efficacy" as a mitigating factor. It is important to investigate what factors could moderate the negative relationship between technostress creators and work-life balance because technostress creators are unavoidable in modern work environments such as office, work field, media studio, newsroom and even classroom especially for teachers having to use ICTs to teach (a trend which is increasingly becoming inevitable more so because of the necessity for people to maintain social distancing as a "new normal" way of life which has been occasioned by the COVID-19 pandemic). This study focuses on personal resources because, personal resources have received less research attention than job resources, particularly in the technostress literature, as noted by Bakker and Demerouti (Bakker, Demerouti, 2017), Apooyin (Apooyin, 2014), and Lehmann-Jacobsen (Lehmann-Jacobsen, 2017). There is evidence that certain job resources, such as the quality of leader-member interaction, can mitigate the positive relationship between technological stressors (i.e., "technology overload") and work-family conflict (see Harris et al., 2015). However, little attention has been paid to the role of personal resources in research. Selfefficacy was examined in this study as a potential moderator (Xanthopoulou et al., 2013). Selfefficacy is a psychological construct that refers to an individual's belief in their ability to succeed in specific situations or complete a specific task (Bandura, 1997). Thus, self-efficacy is a critical personal resource (ten Brummelhuis, Bakker, 2012), serving as a moderator in stressor-strain relationships (Siu et al., 2005).

Additionally, this study focuses on job self-efficacy because specific forms of self-efficacy have a higher predictive value than general self-efficacy (Ma et al., 2021), and technostress creators are job-level demands. According to Schaubroeck et al. (Schaubroeck et al., 2000: 515), "job selfefficacy refers to people's beliefs about their abilities to exert control over" various job situations and events that contribute to their job performance success. For two reasons, this study proposes that job self-efficacy acts as a moderator in the relationship between technostress creators and work-life balance.

To begin, job self-efficacy may act as a buffer against the negative impact of technological stress on employees' work-life balance. Job self-efficacy reflects employees' beliefs about their ability to perform job-related responsibilities and tasks (Jex et al., 2001); thus, job stressors such as technostress creators are likely to pose less of a threat to workers with higher job self-efficacy. Not having to invest additional time or effort in response to technological invasion or complexity may protect workers with higher job self-efficacy from resource depletion and, ultimately, diminished work-life balance (ten Brummelhuis, Bakker, 2012).

Two, self-efficacy in one's job may aid in coping with technostress creators. Employees with a higher sense of job self-efficacy are more likely to use effective coping mechanisms when confronted with job stressors (ten Brummelhuis, Bakker, 2012). Employees with a higher sense of self-efficacy are more likely to employ problem-solving strategies, whereas those with a lower sense of self-efficacy are more likely to employ emotion-focused strategies (Jex et al., 2001). Coping strategies that are problem-focused are more effective at facilitating adaptive responses to job stressors (Kinicki, Latack, 1990).

This study, therefore, presumes that technostress creators are harmful to work-life balance and adaptive responses will be facilitated by job self-efficacy to technostress creators like active coping such and problem solving. Thus, "the negative effects of techno-stressors on work-life balance" may be attenuated. Hence, this study formulated the following hypothesis:

H2: The relationship between technostress creators and work-life balance is moderated by job self-efficacy.

Discussion of the results. The results supported the negative relationship between technostress creators and work-life balance, and the moderating effect of job self-efficacy. That is to say that "job self-efficacy" buffered impacts of technostress creators that are negative on "worklife balance". Because the study is based on a cross-sectional research design, the possibility for the researchers to establish causal relationships among the variables was, however, limited because of that. Hypothesised association between technostress creators and work-life balance that was negative was tested and a boundary condition of the relationship was identified. The result is marvelous; indicating that as a personal resource "job self-efficacy" can buffer the impact of technostress creators that was negative on the work life balance of employees.

Implications of the results for theory. Several theoretical contributions have been made by this study. Firstly, it enriches research on technostress by expanding people's knowledge of the 
effect of technostress creators on the extra-work domains of employees. The existing research and literature centre on the effect of technostress creators on domains related to work with little attention to "work-life balance". Exploring the relationship between technostress creators and work-life balance can enrich the world's knowledge regarding the extensive effects of technostress creators on employees using information and information and communication technologies at work. Although exploratory studies were conducted on the correlation of technostress creators with work-family conflict (see Harris et al., 2011; Harris et al., 2015), work-life balance is different from work-family conflict "because the former embraces various life roles beyond work roles" (Casper et al., 2018 in Ma et al., 2021). Thus, research on problems surrounding seeking to understand balancing work and life uniquely contributes to the literature on technostress. Moreover, this study considers all five dimensions of technostress creators. The unfortunate thing is that past studies had excluded others like "techno-invasion" and "techno-overload" (Ma et al., 2021). Encompassing the whole "scope" of technostress creators causes a better understanding of "their effect on worklife imbalance" as Gaudioso and colleagues (Gaudioso et al., 2017) corroborate.

Secondly, the findings of the present study have contributed toward improving the Job Demands-Resources literature through examining what buffering effect "personal resources" (Bakker, Demerouti, 2017) have on the relationship between technostress causers and "work-life balance." Thus, it contributes to our understanding of the individual employee who are more likely to experience higher negative impact of work-life balance because of technostress creators. This study discovered that a critical personal resource known as "job self-efficacy" mitigates the negative effects of technostress creators on "work-life balance".

Practical implications of the results. The findings of this study have several implications for practice regarding how to assist workers who use ICTs in coping with technostress creators, as the rate of ICT use at work continues to increase in tandem with poor services (e.g., electricity supply, broadband internet service, low remuneration, exorbitant high-end latest technologies, among others), particularly in developing countries.

To begin, the findings imply that workers need to be mindful of the influence of technostress creators on their pursuit of a comfortable work-and-life experience. Because ICT development and advancement are common in many enterprises, managers/employers must consider technology when caring for their employees and, as a result, their performance thus, paving the way for an employee-conscious organisation culture. Organisational culture is the set of processes, professional practices, explicit and implicit rules, organisation, agreements, and ways of thinking shared within an organisation. When these elements are linked to workplace hazards and safety, they help to define a specific safety culture within an organisation, which Von Thaden and Gibbons (Von Thaden, Gibbons, 2008) define as "every member of every group and at every level of the organisation placing a lasting value on worker priorities and public safety." It shows how individuals and groups adhere to personal responsibility for safety, work to maintain, improve, and communicate safety information, strive to learn, adapt, and actively modify (individually and organisationally) behaviour based on lessons learned from errors, and take responsibility for or strive to be honoured in conjunction with these values" (Galimberti, 2014).

Furthermore, Apooyin (Apooyin, 2014), and Richardson (Richardson, 2017) suggest, the findings underscore the importance of organisations exercising caution when recommending, presenting and/or managing novel work technologies for use in daily organisational routine businesses. Turner (Turner, 2016 cited in Ma et al., 2021) mentions the German company Volkswagen AG as an example of a company that disables work emails after regular business times. Policies like that one can play a big role in managing the level of technostress and mitigating its impact on workers, something that can encourage employees to develop positive work attitude toward achieving eventful work-life balance.

Prioritising and caring about workers' "premium goal" of achieving a work-life balance amidst stressful technology-dominated work environment helps toward improvement of their wellbeing, health, and safety as well as their organisations'. Research has shown that work-life balance yields positive organisational results such as increased employee "engagement and commitment" (Apooyin, 2014; Ma et al., 2021). Prioritising employees' comfortable work-and-life experience could aid employers in retaining talented employees. According to a Marie (Marie, 2019) survey, $62.4 \%$ of technologically savvy employees leave their jobs in search of a better work-life balance, particularly in developed societies. Thus, organisations would greatly benefit from assisting their employees in coping with techno stressors to avoid work-life imbalance. 
The moderating effect of job self-efficacy illuminates the strategies for mitigating the negative effects of technostress creators. Technostress creators are an unavoidable part of modern workplaces because of the innovative dynamism accelerated developments in organisational information and communication technologies coupled with rising intense rivalry between organisations. By considering the finding about the regulatory role of self confidence in work using technology, or "job self-efficacy", organisations can deal with unavoidable technostress generators through motivating employees who have a high sense of job self-confidence for consideration for tougher ICT-based jobs, because the findings of the present study show that workers who possess higher levels of job self-confidence are less likely to be stressed down by technostress creators.

Also, organisations could boost the job self-confidence of their employees through training. Given that past research (e.g., Bandura, 1997; Ma et al., 2021) has also demonstrated that employee job selfconfidence, or "job self-efficacy" can be enhanced through training, drill programmes meant to raise workers' job self-confidence may be an efficient means of helping workers to cope with technostress creators, balancing work, and life, and disseminating credible and verifiable information for a better society. Additionally, Apooyin (Apooyin, 2014), Ma et al. (Ma et al., 2021) suggest that organisations could provide "stress management intervention" programmes aimed at assisting workers experiencing stressful "work-life balance caused by organisational techno stressors.

Although ICT has is a critical factor in the creation of technostress for, it can be of immense benefits to both the workers and workplace. Organisatons such as news media and others, their employees, and ICT experts can collaborate in the design of new ICTs or the modification of existing systems to include business processes that support these technologies, thus giving rise to positive ICT. Positive ICTs will stimulate rather than prevent, without proper cooperation. ICTs must be designed in accordance with the organisational safety culture to which it belongs and contributes for any technology or process introduced within an organisation. In this context, for example, organisational culture actions have been suggested to regulate the relationship between organisational outcomes and ICT use (Brivio et al., 2018; Ma et al., 2021). Another example is the shift to the Web 2.0 model necessitates gradually abandoning entrepreneurial processes based on Web 1.0 tools such as email and replacing them with 2.0 tools (such as social media, blogs). This shift may present an opportunity to assess current ICT and related work processes to develop and improve new working methods and technologies to facilitate work-life balance for teaming employees who constantly use ICTs at work. Work processes and techniques based on positive ICTs that are collaboratively designed, on the other hand, make employees' jobs easier, more satisfying, and less stressful thus, paving the way for a positive work-life balance. Employees may be more engaged in collaborative work processes, as a result. Their work-life balance will be maintained as well as technological invasion, technological stress, and technological addiction will be avoided with well-designed ICT operations (see Brivio et al., 2018).

\section{Results}

The descriptive statistics were computed using SPSS version 23, and Table 3 (see Appendix) shows the results of the study.

Table 1. The Model Comparison Results

\begin{tabular}{|c|c|c|c|c|c|c|c|c|c|}
\hline No & Models & $\chi^{2}$ & $\mathrm{df}$ & CFI & TLI & RMSA & SRMR & $\chi^{2}$ & df \\
\hline 1 & $\begin{array}{l}\text { One-factor } \\
\text { Model }\end{array}$ & 2320.55 & 209 & .413 & .413 & .179 & .143 & $1854.80^{* * *}$ & 10 \\
\hline 2 & $\begin{array}{l}\text { Three-factor } \\
\text { Model (i) }\end{array}$ & 734.43 & 203 & .866 & .848 & .088 & .091 & $268.86^{* * * *}$ & 4 \\
\hline 3 & $\begin{array}{l}\text { Three-factor } \\
\text { Model (ii) }\end{array}$ & 963.64 & 203 & .109 & .782 & .109 & .083 & $497.89^{* * *}$ & 4 \\
\hline 4 & $\begin{array}{l}\text { Four-factor } \\
\text { Model }\end{array}$ & 355.65 & 296 & .909 & .933 & .077 & .079 & & \\
\hline
\end{tabular}

Table 1 contains the data of a confirmatory factor analysis (CFA), which, to test the measurement model was first analysed in Mplus v. 7.0 based on Muthen and Muthen's (Muthen, Muthen, 2012) recommendation as cited in Ma et al. (Ma et al., 2021). The scores of the various indices are as follows: Comparative Fit Index (CFI), Turker-Lewis Index (TLI), Root Mean-Squared 
Error of Approximation (RMSEA) and Standardised Root-Mean Residual (SRMR). The data fit which was as follows: $\left[\chi^{2}=355.65, \mathrm{df}=296, \mathrm{CFI}=.91, \mathrm{TLI}=.93, \mathrm{RMSEA}=.08\right.$ and SRMR $\left.=.08\right]$ was confirmed for the outcome of the four-factor model, indicating a significant loading for all the items. So, it should be noted that the "four-factor" model is the appropriate for the data considering the measurement models comparison (see Table 1) and that, based on the outcomes, the measurements were valid.

Furthermore, the one-factor model consists of "Workload + Technostress creators + Job selfefficacy + Work-life balance"; the three-factor (i) model consists of "Workload + Technostress creators, Job self-efficacy + Work-life balance"; the three-factor model (ii) consists of "Workload, Technostress creators + Job self-efficacy, Work-life balance"; while the model with the four factors consists of Technostress creators: "Workload", "Job self-efficacy" and "Work-life balance".

Hypotheses testing. Then general linear modelling analyses was conducted using SPSS v. 23 to test Hypotheses 1 and 2. Technostress creators were significantly associated with work-life balance in a negative way: [ $\beta=-.227, \mathrm{t}=-4.264, \mathrm{p}<.05]$. Regard the first step (step i) if controlling for workload as shown in Tab. 2. Thus, H1 is accepted. Hence, the data in Table 2 confirms the association of work-life balance with technostress creators and job self-efficacy in a significant way: $[\beta=.248, t=3.784$, $\mathrm{p}<$.01]. For this, regard the second step (step ii) in the Table 2.

Employing the analytical test of "simple slope", the present study discovered that the association between "technostress creators" and "work-life balance" which was negative significantly favours employees that relatively have lower levels of work confidence using technology ("lower job self-efficacy levels"): [ $-1 \mathrm{SD}, \beta=-.423, \mathrm{t}=-5.400, P<.01]$, whereas the relationship was not significant for employees with higher levels of working confidence using technology ("higher job self-efficacy levels": $(+1 \mathrm{SD}, \beta=-.012, \mathrm{t}=-.163, P<.05)$. Hence, $\mathrm{H} 2$ is accepted.

These results imply that enterprises such as news media and others, their employees, and technology experts must collaborate in the design of new ICTs or the modification of existing systems to include business processes that support these technologies, thus giving rise to positive ICT capable of facilitating a work-life balance for employees. Positive ICTs will stimulate rather than prevent, without proper cooperation, work-life balance. ICTs must be designed in accordance with the organisational safety culture to which it belongs and contributes for any technology or process introduced within an organisation.

Table 2. Linear Regression Analysis Results ( $\mathrm{n}=297)$

\begin{tabular}{lllll}
\hline Predictors & \multicolumn{2}{l}{ Work-Life Balance } & \\
\cline { 2 - 5 } & Step (i) & Step (ii) & Step (iii) & Step (iv) \\
Variables of Control & & & & \\
AG & & & & \\
GDR & -.059 & -.050 & -.061 & -.057 \\
MS & .022 & .041 & .023 & .011 \\
Education qualification & $-.245^{* *}$ & $-.241^{* *}$ & $-.206^{* *}$ & $-.206^{* *}$ \\
Occupation & -.050 & -.040 & -.037 & -.026 \\
Number of hours in a week & -.048 & -.062 & -.010 & -.010 \\
Workload & $-.225^{* *}$ & $-.247^{* *}$ & $-.231^{* *}$ & $-.231^{* *}$ \\
Independent Variable & $-.238^{* *}$ & $-.264^{* *}$ & -.073 & -.075 \\
Technostress creators & & & & \\
Moderator & $-.227^{*}$ & $-.141^{* *}$ & -.074 & -.071 \\
Job self-efficacy & & & & \\
Interactions & & $.191^{* *}$ & .085 & .081 \\
Technostress creators x Job self-efficacy & & & & \\
R2 (adjusted) & .200 & $.248^{* *}$ & .089 & .086 \\
$\Delta$ R2 & $.012^{*}$ & $.017^{* *}$ & .395 & .393 \\
F & $10.83^{* *}$ & $11.75^{* *}$ & $19.69^{* *}$ & .000 \\
$\Delta$ F & $4.63^{*}$ & $7.143^{* *}$ & $71.756^{* *}$ & .129 \\
\hline
\end{tabular}

Notes: The scores are expressed in "standardised beta coefficients": [*P<.05, **P<.01] 


\section{Conclusion}

The endeavour to seek to strike a balance between work and non-work life could be a valuable ambition for all categories of workers, especially those who use myriads of information and communication technologies with varying degrees of advancement on a regular basis, and managers. Though work-related technologies are nowadays speedily becoming sophisticated leading to the increasingly blurring of "work-life balance for many employees, maintaining a worklife balance continues to become difficult for workers using technologies, a phenomenon that may have a negative impact on their job performance. According to the findings of this study, technostress creators are detrimental to workers' work-life balance. It is hoped that this research will spur the development of additional studies using a Job Demands-Resources Theory perspective (Bakker, Demerouti, 2017) to add to the body of knowledge on technostress and worklife balance among non-working groups such as students. Thus, this study discovered that technological pressures have become significant sources of pressure, strain, anxiety, worry and stress in contemporary organisations; technostress factors are negatively associated with employees' "work-life balance"; and that employees with a high level of self-efficacy function are less susceptible to techno pressures.

This paper argues that technostress is a symptom of a safety culture that does not exist. It is self-evident that any intervention to prevent or reduce technological stress from the excessive or addictive use of ICTs at work must first acknowledge that it is a factor affecting organisational performance. After becoming familiar with technostress, the employer can concentrate on the work, technological, and communication processes involved in this situation. Employees will save time and effort by using well-designed processes and ICTs, preserving their work-life balance, and avoiding "techno-invasion, techno-strain, and "technoaddiction" as Brivio et al. (Brivio et al., 2018: 3) notes. This paper further contends that even though ICT, or technology has been shown to be a critical factor in the creation of technostress for employees (e.g., journalists who use various ICT devices and software in newsgathering, processing, and dissemination), it can help the workers and workplace. Enterprises such as news media and others, their employees, and technology experts can collaborate in the design of new ICTs or the modification of existing systems to include business processes that support these technologies, thus giving rise to positive ICT. Positive ICTs will stimulate rather than prevent, without proper cooperation, a work-life balance. ICTs must be designed in accordance with the organisational safety culture to which it belongs and contributes for any technology or process introduced within an organisation.

In conclusion, this study has made contribution to the technostress research in three ways as follows. First, this study is one of the few to demonstrate the presence of a correlation of technostress creators with work-life balance. Important implications are obtainable in the findings of the present study because of significantly salient role technology has and plays in contemporary organisations and the struggle of workers "to maintain a work-life balance" respectively. Also, this study identifies "a key boundary condition" for the relationship between technostress creators and the balancing of employees' work life, or "work-life balance". To be precise, it shows that individual workers' belief in their abilities to deal with technostress ("job self-efficacy", in this case) may influence their experience in the workplace and home regarding "work-life balance" in the face of technostress creators. Concisely, the present study has filled an important literature void in addition to providing a further understanding of the way employees should go in for work and life comfort despite having to encounter unavoidable technostress because of the use of modern technologies in contemporary organisations.

Limitations and Recommendations for Future Research: This study had several limitations that should be considered when interpreting the data. The employment of data collected via selfreport or self-administrated questionnaire method increases the likelihood of "common method bias" (Podsakoff et al., 2003). However, the bias could be mitigated "when interactive effects" are considered (e.g., Grzywacz, Carlson, 2007; Ma et al., 2021). Additionally, because of the replication in this study of the significant interactive effect of job self-efficacy and techno stressors on "worklife balance" (as was replicated in a study conducted by Ma et al., 2021), future research should seek to collect data from a variety of sources, including students. For example, Tarafdar et al. (Tarafdar et al., 2007) discovered a negative relationship between technostress creators and productivity among American samples, whereas $\mathrm{Tu}$ et al. (Tu et al., 2005) discovered no such relationship between technostress creators and productivity among Chinese samples. Also, further research should be conducted to determine whether these findings are replicable in other contexts 
and wider and diverse groups because the present study focused on practicing journalists who use ICTs at work only. Finally, this study examined self-efficacy in the workplace, a critical personal resource. Other personal resources, such as optimism, personal safety, and self-esteem, may play a moderating role in future research (also see Ma et al., 2021).

\section{Acknowledgements}

This study received support from University of Maiduguri, Nigeria and TNUS - Thai Nguyen University of Science, Vietnam. The authors express sincere appreciation to the Department of Mass Communication, University of Maiduguri and the Faculty of Journalism, Communications and Literature, Thai Nguyen University of Science for their academic and moral support.

\section{References}

Anaeto, 2007 - Anaeto, S.G. (2007). Science and technology journalism. Lagos, Nigeria: Jamiro Press Link.

Apooyin, 2014 - Apooyin, A. (2014). Stress control and management among Nigerian journalists. Asian Journal of Humanities and Social Studies. 2(1): 15-21.

Ayyagari, 2012 - Ayyagari, R. (2012). Impact of information overload and task-technology fit on technostress. In Proceedings of the Southern Association for Information Systems (SAIS 2012) Conference, March 4:18-22. [Electronic resource]. URL: http://aisel.aisnet.org/sais2012/4

Ayyagari et al., 2011 - Ayyagari, R., Grover, V., Purvis, R. (2011). Technostress: Technological antecedents and implications. MIS Quarterly. 35(4): 831-858. DOI: https://doi.org/ $10.2307 / 41409963$

Bakker, Demerouti., 2017 - Bakker, A.B., Demerouti, E. (2017). Job demands-resources theory: Taking stock and looking forward. Journal of Occupational Health Psychology. 22(3): 273-285. DOI: http://dx.doi.org/10.1037/ocpooooo56

Bakker et al., 2005 - Bakker, A.B., Demerouti, E., Euwema, M.C. (2005). Job resources buffer the impact of job demands on burnout. Journal of Occupational Health Psychology. 10(2): 170-180. DOI: http://dx.doi.org/10.1037/1076-8998.10.2.170 Freeman.

Bandura, 1997 - Bandura, A. (1997). Self-efficacy: The exercise of control. New York:

Beam, 2007 - Beam, R.A. (2007). Organisational goals and priorities and the job satisfaction of US journalists. Journalism and Mass Communication Quarterly. 83: 169-85. DOI: https://doi.org/10.1177/107769900608300111

Brislin, 1980 - Brislin, R.W. (1980). Translation and content analysis of oral and written materials. In Triandis, H.C., Berry, J.W. (eds.). Handbook of Cross-Cultural Psychology: Methodology (Vol. 2). Boston: Allyn \& Bacon: 389-444.

Brivio et al., 2018 - Brivio, E., Gaudioso, F., Vergine, I., Mirizzi, C.R., Reina, C., Stellari, A., Galimberti, C. (2018). Preventing technostress through positive technology. Frontiers in Psychology. 9: 1-5. DOI: http://dx.doi.org/10.3389/fpsyg.2018.02569

Brod, 1982 - Brod, C. (1982). Managing technostress: Optimising the use of computer technology. Personnel Journal. 61(10): 753-757.

Brough et al., 2014 - Brough, P., Timms, C., O’Driscoll, M.P., Kalliath, T., Siu, O., Sit, C. (2014). Work-life balance: A longitudinal evaluation of a new measure across Australia and New Zealand workers. International Journal of Human Resource Management. 25(19): 2724-2744. DOI: http://dx.doi.org/10.1080/09585192.2014.899262

Carlson et al., 2017 - Carlson, J.R., Carlson, D.S., Zivnuska, S., Harris, R.B., Harris, K.J. (2017). Applying the job demands resources model to understand technology as a predictor of turnover intentions. Computers in Human Behaviour. 77: 317-325. DOI: http://dx.doi.org/ 10.1016/j.chb.2017.09.009

Casper et al., 2018 - Casper, W.J., Vaziri, H., Wayne, J.H., DeHauw, S., Greenhaus, J. (2018). The jingle-jangle of work-nonwork balance: A comprehensive and meta-analytic review of its meaning and measurement. Journal of Applied Psychology. 103(2): 182-214. DOI: http:// dx.doi.org/10.1037/aploooo259

Chan et al., 2016 - Chan, X.W., Kalliath, T., Brough, P., Siu, O., O’Driscoll, M.P., Timms, C. (2016). Work-family enrichment and satisfaction: The mediating role of self-efficacy and work-life balance. International Journal of Human Resource Management. 27(15): 1755-1776. DOI: http://dx.doi.org/10.1080/09585192.2015.1075574 
Chandra et al., 2012 - Chandra, S., Srivastava, S.C., Theng, Y.L. (2012). Cognitive absorption and trust for workplace collaboration in virtual worlds: An information processing decision making perspective. Journal of the Association for Information Systems. 13(10): 797-835. DOI: http://dx.doi.org/10.17705/1jais.00310

Demerouti et al., 2001 - Demerouti, E., Bakker, A.B., Nachreiner, F., Schaufeli, W.B. (2001). The job demands-resources model of burnout. Journal of Applied Psychology. 86(3): 499-512. DOI: http://dx.doi.org/10.1037//o021-9010.86.3.499

Deuze, 2005 - Deuze, M. (2005). What is journalism? Professional identity and ideology of journalists reconsidered. Journalism. 6(4): 442-464.

Gaudioso et al., 2017 - Gaudioso, F., Turel, O., Galimberti, C. (2017). The mediating roles of strain facets and coping strategies in translating techno-stressors into adverse job outcomes. Computers in Human Behaviour. 69: 189-196. DOI: http://dx.doi.org/10.1016/j.chb.2016.12.041

Galimberti et al., 2016 - Galimberti, C., Gaudioso, F. Bacchini, F. (2016). Tecnostress: Una nuova sfida per la cultura della sicurezza d'impresa. Amb. Sic. Lav. $3: 2-14$. [Electronic resource]. URL: http://hdl.handle.net/10807/78763

Granziera et al., 2021 - Granziera, H., Collie, R., Martin, A. (2021). Understanding teacher wellbeing through job demands-resources theory. In Mansfield, C.F. (ed.). Cultivating teacher resilience: International approaches, applications, and impact. Singapore: Springer: 229-244. DOI: https://doi.org/10.1007/978-981-15-5963-1_14

Greenhaus, Powell, 2017 - Greenhaus, J.H., Powell, G.N. (2017). Making work and family work: from hard choices to smart choices, women and men in management. New York: Routledge.

Grzywacz, Carlson, 2007 - Grzywacz, J.G., Carlson, D.S. (2007). Conceptualising workfamily balance: Implications for practice and research. Advances in Developing Human Resources. 9(4): 455-471. DOI: http://dx.doi.org/10.1177/1523422307305487

Harris et al., 2011 - Harris, K.J., Marett, K., Harris, R.B. (2011). Technology-related pressure and work-family conflict: Main effects and an examination of moderating variables. Journal of Applied Social Psychology. 41(9): 2077-2103. DOI: http://dx.doi.org/10.1111/j.15591816.2011.00805.x

Hollifield et al., 2015 - Hollifield, C.A., Wicks, J.L., Sylvie, G., Lowrey, W. (2015). Media management: A Casebook approach. Routledge.

Hunter et al., 2019 - Hunter, E.M., Clark, M.A., Carlson, D.S. (2019). Violating work-family boundaries: Reactions to interruptions at work and home. Journal of Management. 45(3): 1284308. DOI: http://dx.doi.org/10.1177/0149206317702221

Hunton et al., 2003 - Hunton, J.E., Lippincott, B., Reck, J.L. (2003). Enterprise resource planning systems: Comparing firm performance of adopters and non-adopters. International Journal of Accounting Information Systems. 4(3): 165-184. DOI: https://doi.org/10.1016/S14670895(03)00008-3

Jena, 2015 - Jena, R.K. (2015). Technostress in ICT enabled collaborative learning environment: An empirical study among Indian academicians. Computers in Human Behaviour. 51: 1116-1123. DOI: http://dx.doi.org/10.1016/j.chb.2015.03.020

Jex et al., 2001 - Jex, S.M., Bliese, P.D., Buzzell, S., Primeau, J. (2001). The impact of selfefficacy on stressor-strain relations: Coping style as an explanatory mechanism. Journal of Applied Psychology. 86(3): 401-409. DOI: http://dx.doi.org/10.1037/0021-9010.86.3.401

Kalliath, Brough, 2008 - Kalliath, T., Brough, P. (2008). Work-life balance: A review of the meaning of the balance construct. Journal of Management and Organisation. 14(3): 323-327. DOI: http://dx.doi.org/10.1017/s1833367200003308

Khan, Jarvenpaa, 2010 - Khan, Z., Jarvenpaa, S.L. (2010). Exploring temporal coordination of events with Facebook.com. Journal of Information Technology. 25(2): 137-151. DOI: https://doi.org/10.1057/jit.2010.8

Kinicki, Latack, 1990 - Kinicki, A.J., Latack, J.C. (1990). Explication of the construct of coping with involuntary job loss. Journal of Vocational Behavior. 36: 339-360. DOI: https://doi.org/10.1016/0001-8791(90)90036-2

Lee et al., 2014 - Lee, Y., Chang, C., Lin, Y., Cheng, Z. (2014). The dark side of smartphone usage: Psychological traits, compulsive behavior, and technostress. Computers in Human Behaviour. 31: 373-383. DOI: http://dx.doi.org/10.1016/j.chb.2013.10.047

Lehmann-Jacobsen, 2017 - Lehmann-Jacobsen, E.T. (2017). Inside a contested profession: A comparative study of journalism in Singapore and Vietnam. PhD Dis. University of Copenhagen, 
Denmark. [Electronic resource]. URL: https://static-curis.ku.dk/portal/files/185037597/PhD_ afhandling_Emilie_T_Lehmann_Jacobsen.pdf

Lim, 2013 - Lim, J. (2013). The relationships of online journalists' emotional responses to competitors with job satisfaction, workload, and perception of the quality of the news website. Asian Journal of Communication. 23(2): 209-224.

Ma, 2021 - Ma, J., Ollier-Malaterre, A., Lu, C.-Q. (2021). The impact of techno-stressors on work-life balance: The moderation of job self-efficacy and mediation of emotional exhaustion. Computers in Human Behaviour. 122: 106811. DOI: https://doi.org/10.1016/j.chb.2021.106811

MacDonald et al., 2016 - MacDonald, J.B., Saliba, A.J., Hodgins, G., Ovington, L.A. (2016). Burnout in journalists: A systematic literature review. Burnout Research. 3(2): 34-44.

Matt et al., 2015 - Matt, C., Hess, T., Benlian, A. (2015). Digital transformation strategies. Business Information Systems Engineering. 57(5): 339-343. DOI: http://dx.doi.org/10.1007/s12 599-015-0401-5

Mcafee, 2006 - Mcafee, A.P. (2006). Enterprise 2.0: The dawn of emergent collaboration. MIT Sloan Management Review. 47(3): 38-38. DOI: http://dx.doi.org/10.1109/EMR.2006. 261380

Marie, 2019 - Marie, H. (2019). Tech workers would quit jobs for better work-life balance. [Electronic resource]. URL: https://workplaceinsight.net/tech-workers-quit-jobs-for-better-worklife-balance/

Mazmanian et al., 2013 - Mazmanian, M., Orlikowski, W.J., Yates, J. (2013). The autonomy paradox: The implications of mobile email devices for knowledge professionals. Organisation Science. 24(5): 1337-1357. https://doi.org/10.1287/orsc.1120.0806

Molla, Heeks, 2007 - Molla, A., Heeks, R. (2007). Exploring e-commerce benefits for businesses in a developing country. The Information Society. 23(2): 95-108. DOI: https://doi.org/ 10.1080/01972240701224028

Muthén, Muthén, 2009 - Muthén, L.K., Muthén, B.O. (2009). Mplus. Statistical analysis with latent variables. User's guide, 7. Mplus Short Courses [online], Alexandria, Virginia. [Electronic resource]. URL: http://www.statmodel.com/virg_nov_course.shtml

Mwakaje, 2010 - Mwakaje, A.G. (2010). Information and communication technology for rural farmers' market access in Tanzania. Journal of Information Technology Impact. 10(2): 111-128.

Ngoc, 2016 - Ngoc, M. (2016). "Năm 2016, Ngành TT\&TT Tăng Trưởng 9.3 \%." BAOMOI.COM, December 23, online edition. [Electronic resource]. URL: http://www.baomoi .com/s/c/21155977.epi

Ofili et al., 2014 - Ofili, A.N., Tobin, E.A., Ilombu, M.A., Igbinosun, E.O..., Iniomor, I. (2014). Assessment of job satisfaction, job stress and psychological health of journalists in South-South, Nigeria. International Journal of Medicine and Biomedical Research. 3(3): 209-218. DOI: https://doi.org/10.14194/ijmbr.3.3.9

Pihl-Thingvad, 2015 - Pihl-Thingvad, S. (2015). Professional ideals and daily practice in journalism. Journalism. 16(3): 392-411. DOI: https://doi.org/10.1177/1464884913517658

Podsakoff et al., 2003 - Podsakoff, P.M., MacKenzie, S.B., Lee, J., Podsakoff, N.P. (2003). Common method biases in behavioral research: A critical review of the literature and recommended remedies. Journal of Applied Psychology. 88(5): 879-903. DOI: http://dx.doi.org/ 10.1037/0021-9010.88.5.879

Pollard, 1995 - Pollard, G. (1995). Job satisfaction among newsworkers: The influence of professionalism, perceptions of organizational structure, and social attributes. Journalism \& Mass Communication Quarterly. 72(3): 682-697.

Ragu-Nathan et al., 2008 - Ragu-Nathan, T.S., Tarafdar, M., Ragu-Nathan, B.S., Tu, Q. (2008). The consequences of technostress for end users in organisations: Conceptual development and validation. Information Systems Research. 19(4): 413-433. DOI: http://dx.doi.org/10.1287/ isre.1070.0165

Rao, 2007 - Rao, N.H. (2007). A framework for implementing information and communication technologies in agricultural development in India. Technological Forecasting and Social Change. 74(4): 491-518. DOI: https://doi.org/10.1016/j.techfore.2006.02.002

Richardson, 2017 - Richardson, K.M. (2017). Managing employee stress and wellness in the new millennium. Journal of Occupational Health Psychology. 22(3): 423-428. DOI: http://dx.doi. org/10.1037/ocpooooo66 
Rogelberg, 2007 - Rogelberg, S.G. (Ed.) (2007). Encyclopedia of industrial and organizational psychology. Two-Factor Theory. Vol. 1-2. Thousand Oaks, CA: Sage Publications: 839-840.

Samaha, Hawi, 2016 - Samaha, M., Hawi, N.S. (2016). Relationships among smartphone addiction, stress, academic performance, and satisfaction with life. Computers in Human Behaviour. 57: 321-325. DOI: https://doi.org/10.1016/j.chb.2015.12.045

Schaubroeck et al., 2000 - Schaubroeck, J., Lam, S.S.K., Xie, J.L. (2000). Collective efficacy versus self-efficacy in coping responses to stressors and control: A cross-cultural study. Journal of Applied Psychology. 85(4): 512-525. DOI: http://dx.doi.org/10.1037/0021-9010.85.4.512

Schreurs et al., 2010 - Schreurs, B., van Emmerik, H., Notelaers, G., De Witte, H. (2010). Job insecurity and employee health: The buffering potential of job control and job self-efficacy. Work and Stress. 24(1): 56-72. DOI: http://dx.doi.org/10.1080/02678371003718733

Siemsen et al., 2010 - Siemsen, E., Roth, A., Oliveira, P. (2010). Common method bias in regression models with linear, quadratic, and interaction effects. Organisational Research Methods. 13(3): 456-476. DOI: http://dx.doi.org/10.1177/1094428109351241

Siu et al., 2005 - Siu, O., Spector, P.E., Cooper, C.L., Lu, C.Q. (2005). Work stress, selfefficacy, Chinese work values, and work well-being in Hong Kong and Beijing. International Journal of Stress Management. 12(3): 274-288. DOI: http://dx.doi.org/10.1037/1072-5245.12. 3.274

Spector, Jex, 1998 - Spector, P.E., Jex, S.M. (1998). Development of four self-report measures of job stressors and strain: Interpersonal conflict at work scale, organisational constraints scale, quantitative workload inventory, and physical symptoms inventory. Journal of Occupational Health Psychology. 3(4): 356-367. DOI: http://dx.doi.org/10.1037/1076-8998.3.4.356

Spreitzer, 1995 - Spreitzer, G.M. (1995). Psychological empowerment in the workplace: Dimensions, measurement, and validation. Academy of Management Journal. 38(5): 1442-1465. DOI: http://dx.doi.org/10.2307/256865

Stamm, Underwood, 1993 - Stamm, K., Underwood, D. (1993). The relationship of job satisfaction to newsroom policy changes. Journalism Quarterly. 70(3): 528-541.

Stamm et al., 1995 - Stamm, K., Underwood, D., Giffard, A. (1995). How pagination affects job satisfaction of editors. Journalism \& Mass Communication Quarterly. 72(4): 851-862.

Syrek et al., 2013 - Syrek, C.J., Apostel, E., Antoni, C.H. (2013). Stress in highly demanding IT jobs: Transformational leadership moderates the impact of time pressure on exhaustion and work-life balance. Journal of Occupational Health Psychology. 18(3): 252-261. DOI: http://dx.doi.org/10.1037/aoo33085

Tarafdar et al., 2019 - Tarafdar, M., Cooper, C.L., Stich, J.F. (2019). The technostress trifecta-techno eustress, techno distress and design: Theoretical directions and an agenda for research. Information Systems Journal. 29(1): 6-42. DOI: http://dx.doi.org/10.1111/isj.12169

Tarafdar et al., 2014 - Tarafdar, M., Pullins, E.B., Ragu-Nathan, T.S. (2014). Examining impacts of technostress on the professional salesperson's behavioral performance. Journal of Personal Selling and Sales Management. 34(1): 51-69. DOI: http://dx.doi.org/10.1080/ o8853134.2013.870184

Tarafdar et al., 2011 - Tarafdar, M., Tu, Q., Ragu-Nathan, T.S., Ragu-Nathan, B.S. (2011). Crossing to the dark side: examining creators, outcomes, and inhibitors of technostress. Communications of the ACM. 54(9): 113-120. DOI: http://dx.doi.org/10.1145/1995376.1995403

Tarafdar et al., 2007 - Tarafdar, M., Tu, Q., Ragu-Nathan, B.S., Ragu-Nathan, T.S. (2007). The impact of technostress on role stress and productivity. Journal of Management Information Systems. 24: 301-328. DOI: http://dx.doi.org/10.2753/MISo742-1222240109

ten Brummelhuis, Bakker, 2012 - ten Brummelhuis, L.L., Bakker, A.B. (2012). A resource perspective on the work-home interface: The work-home resources model. American Psychologist. 67(7) : 545-556. DOI: http://dx.doi.org/10.1037/ao027974

Tu et al., 2005 - Tu, Q., Wang, K., Shu, Q. (2005). Computer-related technostress in China. Communications of the ACM. 48(4): 77-81. DOI: http://dx.doi.org/10.1145/1053291.1053323

Turner, 2016 - Turner, Z. (2016). 'Das Burnout': An epidemic in Germany. The Wall Street Journal, 23 May. [Electronic resource]. URL: http://www.wsj.com/articles/dasburnout-an-epid emic-in-germany-1464023945

Vranjes et al., 2017 - Vranjes, I., Baillien, E., Vandebosch, H., Erreygers, S., De Witte, H. (2017). The dark side of working online: Towards a definition and an Emotion Reaction model of 
workplace cyberbullying. Computers in Human Behaviour. 69: 324-334. DOI: https://doi.org/10.1016/j.chb.2016.12.055

Wayne et al., 2017 - Wayne, J.H., Butts, M.M., Casper, W.J., Allen, T.D. (2017). In search of balance: A conceptual and empirical integration of multiple meanings of work-family balance. Personnel Psychology. 70(1): 167-210. DOI: http://dx.doi.org/10.1111/peps.12132

Xanthopoulou et al., 2013 - Xanthopoulou, D., Bakker, A.B., Fischbach, A. (2013). Work engagement among employees facing emotional demands: The role of personal resources. Journal of Personnel Psychology. 12(2): 74-84. DOI: http://dx.doi.org/10.1027/1866-5888/a000085

$\mathrm{Yu}, 2021-Y u, Q$. (2021). A review of job satisfaction in journalism. Southwestern Mass Communication Journal (SWECJMC). 36(2): 1-17.

\section{Appendix}

Table 3. The Results of the Descriptive Statistics, Reliabilities and Inter-Correlations ( $\mathrm{n}=297)$

\begin{tabular}{|c|c|c|c|c|c|c|c|c|c|c|c|c|c|}
\hline S/No & Variables & "Mean" & "SD" & $\mathrm{i}$ & ii & iii & iv & $\mathrm{v}$ & vi & vii & viii & ix & $\mathrm{x}$ \\
\hline 1 & AG & 29.72 & 2.67 & - & & & & & & & & & \\
\hline 2 & GDR & 1.22 & .56 & $-.13^{*}$ & - & & & & & & & & \\
\hline 3 & Marital status & 1.50 & .50 & $-49^{* * *}$ & .04 & - & & & & & & & \\
\hline 4 & Education qualification & 1.22 & .42 & $.16^{* * *}$ & -.02 & $\begin{array}{l}- \\
.19^{* * *}\end{array}$ & - & & & & & & \\
\hline 5 & Job tenure & 33.71 & 28.27 & $.32^{* * *}$ & .06 & -.25 & $\begin{array}{l}- \\
.16^{* * *}\end{array}$ & - & & & & & \\
\hline $\begin{array}{l}6 \\
7\end{array}$ & $\begin{array}{l}\text { Hours per week } \\
\text { Workload }\end{array}$ & $\begin{array}{l}45 \cdot 34 \\
2.12\end{array}$ & $\begin{array}{l}11.44 \\
.74\end{array}$ & $\begin{array}{l}.12^{*} \\
-.07\end{array}$ & $\begin{array}{l}-.10 \\
-.08\end{array}$ & $\begin{array}{l}-.08 \\
.01\end{array}$ & $\begin{array}{l}.06 \\
-.10\end{array}$ & $\begin{array}{l}.14^{*} \\
.11\end{array}$ & $\begin{array}{l}- \\
.31^{* * *}\end{array}$ & $(.90)$ & & & \\
\hline 8 & Technostress creators & 4.38 & .87 & .04 & -.05 & -.09 & -.05 & .02 & $.18^{* *}$ & $.31^{* * *}$ & $(.75)$ & & \\
\hline 9 & Job self-efficacy & 4.59 & .75 & .02 & -.09 & -.06 & -.02 & .06 & .10 & .11 & -.01 & $(.87)$ & \\
\hline 10 & Work-life balance & 4.79 & 1.15 & .02 & .05 & $-17^{* *}$ & .01 & -.05 & $-{ }^{-} .32^{* *}$ & $-{ }^{-} .34^{* *}$ & $\begin{array}{l}- \\
.21^{* *}\end{array}$ & $.16^{* *}$ & $(.90)$ \\
\hline
\end{tabular}

Notes: $\mathrm{SD}=$ standard deviation; GDR = Gender: $[\mathrm{i}=$ male, $\mathrm{ii}=$ female $]$; Marital status: $[\mathrm{i}=$ married, ii = single]; Educational qualification: $[\mathrm{i}=$ first degree or lower, $\mathrm{ii}=\mathrm{MSc}$ or higher]; Occupation was computed on a monthly basis. Hours per week were computed on an hourly basis; $\left[* \mathrm{P}<.05^{*}, * * \mathrm{P}<.01\right.$, two-tailed test $]$ 